\title{
Portugal e República Dominicana: De um “Plano Português" inovador para o turismo Dominicano (1995-1997) à realidade atual (2016)
}

\author{
Portugal and the Dominican Republic: From an innovative 'Portuguese \\ Plan' for Dominican tourism (1995-1997) to current reality (2016)
}

\author{
Jorge Mangorrinha \\ Universidade Lusófona de Humanidades e Tecnologias, Portugal \\ jorge.mangorrinha@ulusofona.pt
}

\begin{abstract}
Resumo
Há vinte anos, concluiu-se o primeiro plano de ordenamento turístico que uma equipa portuguesa realizou no estrangeiro. Em duas dezenas de anos, a República Dominicana transformou-se turisticamente e tem sido um dos destinos preferenciais dos portugueses. Verifica-se que o planeamento turístico possui uma base de relação muito próxima com a história e a cultura, para além de que a história é essencial, também, para que, no presente, se tracem caminhos de futuro no turismo mundial e no espaço ibero-americano em particular, atendendo à rede possível de trocas, circuitos e rotas entre os dois lados do Atlântico, nos tempos atuais e futuros.
\end{abstract}

Palavras-chave: planeamento turístico; Portugal; República Dominicana.

\begin{abstract}
Twenty years ago, we were the first Portuguese hands-on team abroad to carry out a Tourism planning project, and in two decades the Dominican Republic has transformed itself tourism-wise and has been a preferred destination of the Portuguese ever since. It can be seen that tourism planning has a very close relationship with history and culture; furthermore, history is essential so that in the present, pathways for the future in global tourism may be drawn and in particular in the Ibero-American area, in the light of the network of possible exchanges, circuits and routes between both sides of the Atlantic, in current and future times.
\end{abstract}

Keywords: tourism planning; Portugal; Dominican Republic.

\section{Introdução}

O primeiro "turista” a visitar a República Dominicana foi Cristóvão Colombo. Mas mais de cinco séculos depois este país caribenho foi um território de descoberta para uma equipa de consultores portugueses que, a partir de 1995 e durante mais dois anos, planeou o futuro. Há vinte anos, portanto, esteve nas nossas mãos o primeiro plano de ordenamento turístico que uma equipa portuguesa realizou no estrangeiro. E em duas dezenas de anos a República Dominicana transformou-se turisticamente e tem sido um dos destinos preferenciais dos portugueses. Será que evoluiu segundo as recomendações do Plano Nacional de Ordenamento do Território Turístico, designadamente respeitando valores de sustentabilidade, sobretudo num contexto de "turismo de massas"? Que doutrina ficou deste

\footnotetext{
${ }^{1}$ Parte do texto desta Introdução foi originalmente editado na revista Publituris (Mangorrinha, 2015). 
plano pioneiro, tanto para esse território, como para o universo do planeamento turístico à escala global? E o que é que Portugal beneficiou com isso?

Este plano foi possível através do financiamento do Governo português junto do Banco Interamericano de Desenvolvimento, seguido da revisão e atualização de documentos dispersos existentes, da formulação de estratégias e do desenho de novas zonas de atrativo ecoturístico que motivassem o interesse por parte do setor privado.

A equipa de consultores enfrentou este desafio com um pioneirismo sempre motivador. A elaboração do Plano induzia, para além do rigor técnico, uma necessária criatividade por parte dos futuros planificadores e investidores, em relação a assuntos importantes e transversais em todo o mundo, como a capacidade de carga das praias, a diversificação da oferta turística mediante a exploração do potencial do ecoturismo e a criação de rotas que permitissem aos visitantes conhecerem outros recursos, sem estarem condicionados ao distintivo principal do produto turístico "sol e praia". A necessidade de dotar o país de melhores condições infraestruturais e de segurança foi uma preocupação nossa, de forma a atingir níveis de sustentabilidade, no primeiro caso, e de estimular o turista a percorrê-lo, no segundo caso. Também se revelou importante sublinhar o território cultural e arquitetónico muito para além dos "resorts" turísticos, como novo interesse de busca e conhecimento de um país muito mais surpreendente do que aquilo que é difundido nos meios convencionais de promoção turística.

As praias de areias brancas, as águas cristalinas e os hotéis populares com "tudo incluído", para turistas de classe média, são marcas registadas da República Dominicana, mas essa oferta amplia-se com outro tipo de elementos para classes mais elevadas de turistas, designadamente o "turismo residencial". A República Dominicana recebe, anualmente, mais de 4 milhões de visitantes, sendo o primeiro destino charter em Portugal, e a capacidade hoteleira eleva-se a mais de 100.000 camas oficiais. O turismo representa $15 \%$ do PIB dominicano e cresce $10 \%$ ao ano. ${ }^{2}$

Para tal, muito contribuiu a expansão dos investimentos em locais identificados como de grande potencial turístico, onde nasceram novos "resorts", marinas, parques temáticos e campos de golfe. Os maiores investidores são espanhóis, norte-americanos, alemães, franceses, canadianos, chineses, israelitas e ingleses, ou mistos com financiadores locais, o que revela que o Estado português não acompanhou os resultados de um plano pioneiro feito por técnicos portugueses com o estímulo aos investidores nacionais, apenas potenciado pelo interesse dos portugueses por este país durante os períodos de férias. Mas também tem sido relevante o investimento nas infraestruturas públicas e nos melhoramentos urbanos, tal como preconizámos como sendo tarefa do Estado dominicano.

O balanço que se faz revela uma realidade que se repete em muitos outros locais do mundo e no nosso país em particular: a politização das estratégias para o turismo e os interesses económicos prevalecentes impedem que o planeamento seja a matriz fundamental do ordenamento territorial, nem sempre sendo cumprido ou então servindo fins políticos para justificar a adjudicação de outros planos que revêm os anteriores, ao mesmo tempo que os investimentos se sucedem a uma velocidade que o planeamento não consegue acompanhar.

\footnotetext{
${ }^{2}$ Os números referem-se ao cruzamento de informações provenientes de dados recolhidos com diferentes origens e que confirmam as principais fontes (Banco Central da República Dominicana e Secretaria de Estado do Turismo). $O$ ano de 2013 foi o primeiro em que se ultrapassaram os 4 milhões de visitantes (internos e estrangeiros).
} 
Este país insular (divide a ilha com o Haiti) é rico em história e tornou-se num dos destinos turísticos mais excitantes do mundo, oferecendo uma mescla de sabores locais e europeus. A independência nacional foi conquistada em fevereiro de 1844, mas entretanto, em 1861, a Espanha voltou a exercer domínio no país, que só obteve total autonomia em 1865. No século XX, foi marcado por diferentes regimes políticos, designadamente uma ditadura (1930-1961) e uma intervenção direta norte-americana (1961-1966). O alto nível de corrupção e as políticas ditatoriais enfraqueceram-no, socialmente. Mas há cerca de meio século que o turismo passou a ser visto como uma atividade económica de futuro, embora ainda com poucos aportes para as populações residentes. Punta Cana é o destino mais frequentado pelos turistas estrangeiros, seguido da capital Santo Domingo e de Puerto Plata, sendo que os produtos "sol e mar" e "golfe" são os mais procurados.

Se há vinte anos estávamos (incluído o autor) registados 20 portugueses residentes, hoje estes atingem quase duas centenas. A criação de uma Câmara de Comércio, Indústria e Turismo entre Portugal e a República Dominicana (associação privada, sem fins lucrativos, constituída a 12 de julho de 2013) e a instalação, em Santo Domingo, da Casa de Portugal, para promover a cultura, os produtos lusos e a língua portuguesa, vêm ao encontro de uma das oportunidades propostas pelo Plano, ou seja, a criação de um polo aglutinador dos dois povos, para dinamizar a troca de ideias e de projetos, sendo o turismo o setor-chave, mas alcançando um conjunto de negócios nas áreas das telecomunicações, energia, ensino, agricultura e comércio, numa visão estratégica global.

Assim sendo, este artigo propõe-se analisar a evolução do território turístico dominicano, à luz da sucessão de planos e estudos, desde o Plano da equipa portuguesa até à atualidade, auxiliando-se de uma metodologia de análise de conteúdo e de uma estrutura que apresente as características do território e do seu potencial turístico, de modo a identificar continuidades estratégicas presentes que foram enfatizadas naquele Plano.

\section{O Plano Nacional de Ordenamento do Território Turístico}

\subsection{0 território}

A República Dominicana confronta a norte com o Oceano Atlântico, a oriente com a ilha de Porto Rico, a sul com o Mar das Caraíbas e a ocidente com o Haiti. As ilhas Beata e Saona pertencem ao território dominicano. A sua localização geográfica conferiu-lhe o potencial de ser um dos principais destinos turísticos de "sol e praia", mas há mais para além das praias de areia branca - vales exuberantes, zonas desérticas com formações de dunas e imponentes cadeias montanhosas, vistas panorâmicas, vestígios arqueológicos, monumentos arquitetónicos e zonas submarinas de interesse histórico e cultural. Os principais recursos naturais são os agrícolas, silvícolas e paisagísticos. Existe uma grande diversidade de fauna e flora, que vive e se desenvolve principalmente num sistema de áreas protegidas constituído por numerosos Parques Naturais (Los Haitises, Montecristi, Isla Cabritos no Lago Enriquillo, Sierra de Bahoruco, Jaragua, José Armando Bermúdez, José del Carmen Ramirez, Juam Bautista Pérez Rancier, no Valle Nuevo, etc.).

O território é fértil, húmido e montanhoso, cerca de $80 \%$ está coberto por grandes cadeias montanhosas, sendo o Pico Duarte $(3.175 \mathrm{~m})$ o ponto mais alto. De entre as numerosas correntes fluviais, destacam-se os rios Yaque del Norte e Yuna, a norte, e os rios Yaque del Sur e Ozama, a sul. O lago salgado Enriquillo está situado a sudoeste. A linha de costa é irregular, devido à presença de numerosas baías que formam portos naturais, como as baías de Neiba e de Ocoa, na costa caribenha, e a de Samaná, na costa Atlântica. O clima é tropical, de calor 
húmido, mas moderado. A partir de diferentes dados perfeitamente indiscutíveis, poder-se-á afirmar que as terras baixas registam temperaturas superiores a $23^{\circ} \mathrm{C}$ durante todo o ano, sendo que o período mais húmido decorre de maio a dezembro; durante os meses de verão, as temperaturas oscilam entre $26^{\circ}$ e $32^{\circ} \mathrm{C}$, excepto terras elevadas, mais frias. Ocasionalmente ocorrem ciclones tropicais no Atlântico, entre os meses de agosto e outubro (Arespacochaga, 1968; Sociedade Nacional de Empreendimentos e Desenvolvimento Económico, 1997).

A economia dominicana apresenta-se com dois perfis distintos: a doméstica, cujos setores dinâmicos de crescimento têm sido as comunicações, a construção, a eletricidade, o comércio e os transportes; e a externa, cujas principais variáveis de crescimento têm sido as zonas francas industriais e o turismo (Sociedade Nacional de Empreendimentos e Desenvolvimento Económico, 1997; Ministerio de Economía, Planificación y Desarrollo, 2009).

O turismo é, sem dúvida, uma das atividades económicas de maior crescimento no mundo e uma das que melhor consegue desenvolver os territórios, pois beneficia diretamente as economias. O turismo tem despertado o interesse dos governos de países em vias desenvolvimento pela sua capacidade de gerar divisas e de favorecer o investimento privado, o desenvolvimento de empresas locais e a criação de emprego. A partir dos anos 70 e 80 do século passado, diferentes governos caribenhos promoveram o turismo, como setor impulsionador do crescimento económico. Coincidindo com a expansão do "turismo de massas", nestas décadas, construíram-se grandes centros turísticos, que beneficiaram de investimentos públicos em infraestruturas e incentivos para o investimento privado. $\mathrm{O}$ êxito de uma grande parte dos investimentos de grandes empresas e o primado do crescimento quantitativo contribuíram para difundir a ideia de que o turismo devia ser essencialmente uma atividade privada e de mercado, portanto, com alto nível de competitividade.

Esta lógica de atuação originou crescimentos rápidos em países em desenvolvimento, designadamente insulares, pondo em perigo a sustentabilidade dos territórios, quando o crescimento foi acompanhado pela ausência ou escassez de planeamento. O modelo turístico mais aplicado nas Caraíbas foi, inicialmente, o "sol e praia", em "grande hotel-resort", sobretudo de cadeias hoteleiras internacionais e localizados na linha de costa, na modalidade de "tudo incluído" e controlado em termos comerciais por grandes e médios operadores internacionais e só excepcionalmente por grupos locais.

\subsection{Antecedentes históricos}

A atividade turística iniciou-se, formalmente, na República Dominicana, quando se promulgou a Lei n. ${ }^{\circ} 103$, de 1931, sobre automóveis para turistas, e depois com a promulgação da Lei n. ${ }^{\circ}$ 4378 , de 1934, sobre o sistema de direção e organização das atividades turísticas, as quais tiveram transformações nas décadas seguintes. A oportunidade turística da República Dominicana foi potenciada pelo isolamento imposto pelos Estados Unidos a Cuba, no final da década de 1950 pois, na sequência desta atitude, os investimentos europeus e norteamericanos foram redimensionados para outros territórios próximos. A República Dominicana foi um desses casos, mas ainda assim durou algum tempo a iniciar esse processo. Em meados dos anos 60, com uma extensão equivalente a dez vezes as llhas Baleares, era efetivamente o destino turístico das Caraibas com apenas cerca de 45.000 visitantes (Arespacochaga, 1968). No final dessa década, foi criada a Corporação de Fomento da Indústria Hoteleira e Desenvolvimento do Turismo, para coordenar a promoção turística e o financiamento das empresas hoteleiras e turísticas em geral, sendo que o Estado dominicano controlou, até aos 
anos 70, quase todo o investimento turístico, mas ainda escasso. Esse esforço foi realizado graças ao empenho do presidente Joaquín Balaguer e de Ángel Miolán, o ideólogo do turismo dominicano. Ambos seriam os promotores de um primeiro plano orientador para o futuro do país, na perspetiva das suas potencialidades turísticas, redigido por um consultor espanhol, engenheiro Juan de Arespacochaga, e financiado pela UNESCO.

Esta entidade promoveu um plano de aproveitamento turístico com objetivos essencialmente de valorização cultural - "com anterioridade a esta misión, hubiera destacado ya otros expertos en relación con la revalorización de los monumentos culturales existentes en la República Dominicana e muy concretamente en la capital de Santo Domingo" (Arespacochaga, 1968: 1). Em termos gerais, esse plano pretendia desenvolver a consciência sobre a necessidade de desenvolver esta atividade, como motor económico do país, face às dificuldades patentes na época. No plano, relevam-se os impulsos turísticos anteriores de Cuba, num primeiro período, e depois de Porto Rico, Bahamas, Jamaica, Trinidad e Tobago, designadamente. Nele, são referidas as razões do atraso turístico dominicano:

(1) Falta de uma política ativa de suficiente intensidade para atraír turismo externo;

(2) Inadequada qualidade da oferta face às perspetivas de crescimento da procura turística;

(3) Situações de transição e conflito político interno, geradoras de um clima de insegurança não atrativo para o turismo (Arespacochaga, 1968: 8).

O trabalho partiu do pressuposto de que não havia um processo de desenvolvimento mais direto, mais rápido e mais viável do que aquele que se podia alcançar através da expansão do turismo dominicano. A ideia passava por considerarações que levassem a República Dominicana a atingir valores próximos dos paraísos turísticos da época (México e Florida) e superar Porto Rico. Arespacochaga, conhecedor do "milagre" espanhol desde o final dos anos 50, calculava um crescimento exponencial para o turismo dominicano, com base em polos, dando particular enfoque a Macao, ou seja, o que hoje se considera Bávaro e Punta Cana, na costa Leste, com mais de $100 \mathrm{~km}$ de praias virgens, propícias aos investimentos privados de grande escala e com isenções fiscais para que eles fossem imediatos, mas também públicos, em infraestruturas, mediante empréstimo externo.

Seria a base estratégica política de desenvolvimento da República Dominicana à luz do seu potencial turístico. Promulga-se a Lei n. ${ }^{153}$, de 1971, sobre Promoção e Incentivo ao Desenvolvimento Turístico, dois anos depois do investimento multimilionário de um fundo de pensões norte-americano em terrenos litorais virgens em Punta Cana, na posse de Frank Rainieri, e com apoio financeiro do Banco Mundial, primeira resposta às diretivas do estudo referido (1968), quanto ao despertar do interesse puramente privado. Frank Rainieri associouse ao investidor norte-americano Theodore W. Kheel. para impulsionar o projeto das primeiras cabanas turísticas em Yauya ou Punta Borrachón (atual Punta Cana). ${ }^{3}$

A nova regulação do turismo dominicano, decretada em 1979 (Lei n. ${ }^{\circ} 84$ ), determina que a Secretaria de Estado de Turismo deve, designadamente, programar, dirigir e avaliar as atividades turísticas no país, os investimentos no setor e as campanhas promocionais; determinar e supervisionar as regiões turísticas, as delegações de promoção turística nacionais

\footnotetext{
${ }^{3}$ Este investimento foi o início do que viria a ser o Grupo Punta Cana, formado pelas empresas Punta Cana Beach and Golf, Punta Cana Resort and Club, Escuela Internacional Punta Cana, Corporación Aeroportuaria del Este, Punta Cana Yacht Club, Corporación Turística y de Servicios Punta Cana e Guardianes del Este.
} 
e internacionais; orientar a construção de infraestruturas no setor; e controlar os operadores turísticos. Como consequência, há uma procura acrescida nos investimentos, designadamente, de nomes de projeção internacional. O costureiro Oscar de la Renta e o cantor Julio Iglesias constroem residências em Punta Cana, passando a ser acionistas do Grupo Punta Cana, e os irmãos Barceló abandonam Porto Rico e implantam-se em Bávaro.

Os anos 80 foram de prosperidade e, como tal, justificava-se um novo pensamento estratégico sobre este território turístico. O Plano Nacional de Ordenamento Territorial Turístico da República Dominicana foi publicado em novembro de 1990, mediante um convénio entre o Banco Interamericano de Desenvolvimento e a Secretaria de Estado de Turismo. Nele, organizam-se informações relativas às diferentes áreas turísticas em desenvolvimento e com potencial. Foi, além do mais, um trabalho que pretendeu organizar e definir o modo em que cada uma destas áreas devia ser desenvolvida. Os objetivos gerais definidos foram:

(1) Desenhar e concretizar um turismo equilibrado;

(2) Melhorar o nível de qualidade do produto;

(3) Preservar o ambiente.

Sob um marco conceptual definido, numa hierarquia a três escalas - "Espaço de Interesse Turístico", "Zonas Turísticas” e "Áreas Turísticas" -, foram estabelecidas sete Zonas Turísticas (Montecristi, Puerto Plata, Samaná, Zona Este, La Romana, Santo Domingo e Zona Sul), para as quais se determinaram sistemas de planeamento integrado com níveis de vigência e de intervenção - até 1995, a longo prazo e nos planos locais. Estes últimos apresentavam-se com grandes debilidades, limitando-se aos aspetos infraestruturais e arquitetónicos (Ministério de Turismo, 1999). O "Espaço de Interesse Turístico" desenvolve-se pela costa marítima numa largura de 5 km, a "Zona Turística” possui uma ou mais “Áreas Turísticas" e, como mínimo, dez polos de atração importantes (não definidos), localizados à distância de até $100 \mathrm{~km}$ do centro principal. Delimitam-se catorze Áreas Turísticas e, nestas, unidades turísticas com um centro turístico e mais de três polos de atração importantes (não definidos). O "Centro Turístico" é definido como aglomerado urbano com raio de influência, real ou potencial, suficiente para motivar uma viagem turística.

Definiram-se "Áreas Aproveitáveis", tomando em conta os níveis de restrições, categorizando-as em mínimas, moderadas e a preservar. Para cada Área ou Centro Turístico, definiu-se uma densidade bruta determinada com base em critérios ambientais, físicos e de imagem. Tal densidade foi multiplicada pela área aproveitável, determinando assim a capacidade de carga em número de alojamentos turísticos.

O crescimento turístico era mais relevante, na época, na Zona Este, Samaná, Barahona e La Isabela-Luperón, para uma procura nacional na ordem dos 1.380 .000 turistas por ano, estimando-se a procura potencial, para 1995, em 2,7 milhões de turistas. Esta projeção assumiu uma taxa de crescimento nas Caraíbas duas vezes maior do que a mundial, apesar de que para a República Dominicana se assumia uma taxa de crescimento duas vezes maior do que a das Caraíbas.

Na vigência deste Plano, dá-se uma verdadeira operação regeneradora na Zona Colonial de Santo Domingo, tendo em vista as comemorações do quinto centenário da chegada de Cristóvão Colombo (1492-1992), facto muito enfatizado aquando da presença dos consultores portugueses (1995-1996) e que comprovámos no local. A Zona Colonial foi reconhecida pela 
UNESCO como valor universal e excepcional, em 1990, por ser a capital das Índias Ocidentais e o ponto de partida para a influência cultural europeia. Cidade das primeiras vezes, Santo Domingo foi a sede das primeiras instituições nas Américas: a Catedral de Santa Maria da Encarnação, o Mosteiro St. Francis, a Universidade Santo Tomás de Aquino, o Hospital Nicholas Bari, a Casa de Contratação. É, também, a primeira cidade murada (Fortaleza de Santo Domingo e Torre del Homenaje) e a primeira sede do poder espanhol no Novo Mundo. Com o seu património e os edifícios monumentais e únicos nesta região, a Zona Colonial de Santo Domingo mantém, no essencial, a estrutura, os usos e as funções que caracterizaram os primeiros edifícios da sua fundação, preservando a sua integridade e autenticidade.

\subsection{O Plano}

O Plano Nacional de Ordenamento do Território Turístico da República Dominicana partiu do princípio de que, de acordo com a importância do setor turístico para o desenvolvimento económico, cultural e social do país, se deviam aplicar ações e estratégias devidamente planeadas e de maneira objetiva. Fundamentalmente, o Plano criou uma metodologia de apoio à decisão.

Figura 1. Espaço de Interesse Turístico da República Dominicana, desenho de novembro de 1996

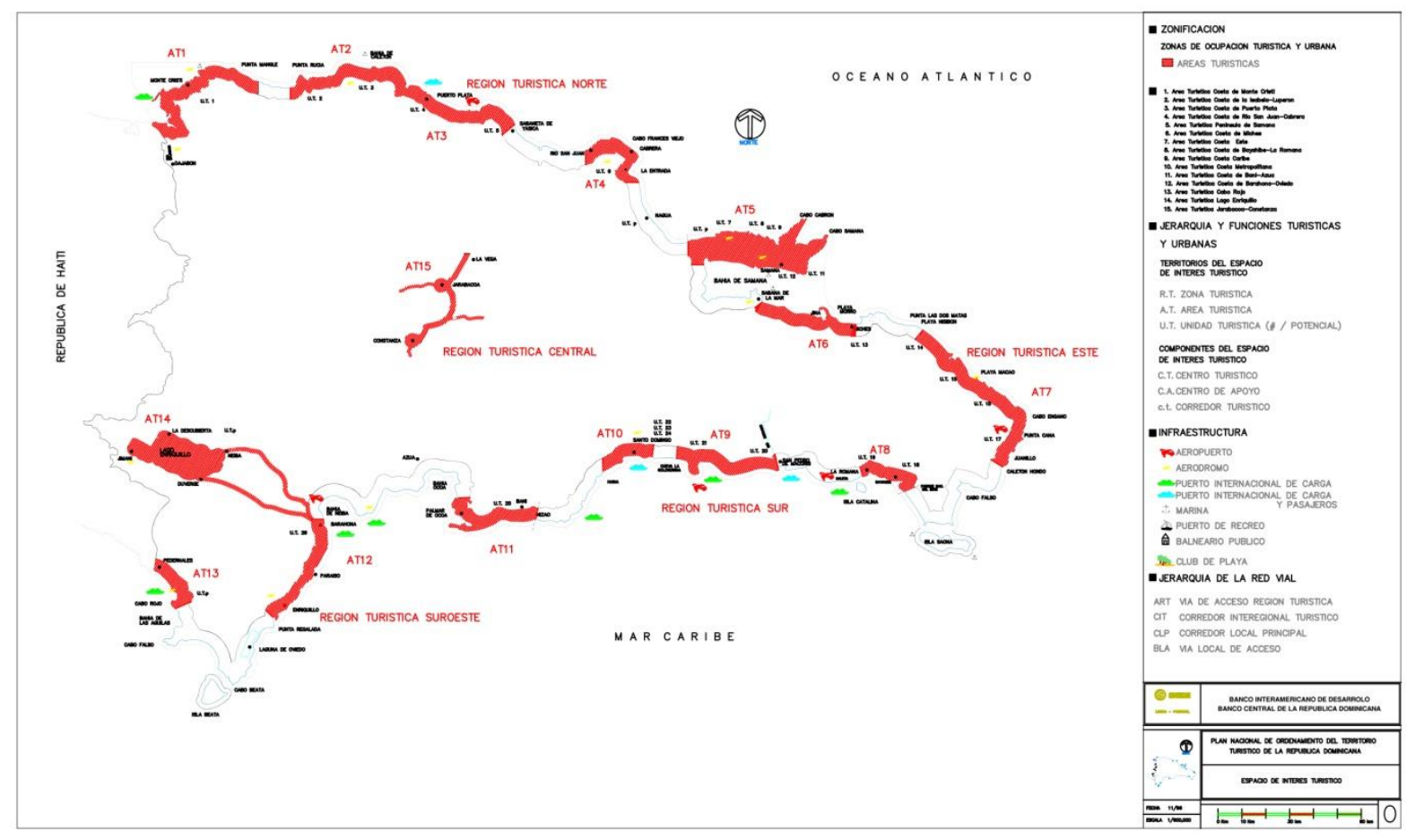

Fonte: Sociedade Nacional de Empreendimentos e Desenvolvimento Económico (1997)

O documento afirma que a República Dominicana vivia um momento de grande transformação e evolução, pelo que a elaboração de um esquema de ordenamento territorial turístico exigia uma reflexão estruturada e justificada. Devido à inexistência de um macroplano regulador da atividade turística, este Plano propunha-se facilitar e orientar as formas mais vantajosas de utilização do espaço turístico. 
Quanto às estratégias e objetivos, partiu-se da ideia de que o futuro do destino dependia de um planeamento, de uma regulação e de uma comercialização coerentes, tanto a nível nacional como internacional. Por outro lado, as perspetivas e o planeamento, do turismo, a longo prazo, deviam ter em consideração o equilíbrio entre o desenvolvimento turístico e a conservação dos três conjuntos de recursos (naturais, histórico-patrimoniais e costumes).

Neste contexto, definiram-se três grandes objetivos:

(1) Turismo equilibrado;

(2) Melhoria do nível da qualidade;

(3) Preservação do ambiente.

Por sua vez, os princípios do Plano passavam por:

a) Definir zonas com interesse turístico;

b) Fixar prioridades para o desenvolvimento turístico de cada região;

c) Sugerir os tipos de turismo e a localização de atividades e empresas;

d) Estabelecer normas urbanísticas, ambientais e infraestruturais.

De um modo genérico, apontavam-se as estratégias gerais para alcançar os objetivos fundamentais:

Turismo equilibrado

1. Controlar e estimular o crescimento turístico da região;

2. Impedir o crescimento desordenado;

3. Ajustar a oferta à procura;

4. Especializar áreas para mercados específicos;

5. Especializar áreas para produtos específicos;

6. Alcançar os níveis previstos nas propostas sobre infraestruturas;

7. Sensibilizar a população sobre a importância do turismo.

Melhorar o nível de qualidade

1. Recuperar produto turístico;

2. Criar mecanismos que impossibilitam a regressão da qualidade do produto;

3. Valorizar os aspetos culturais, históricos e arquitetónicos;

4. Integrar o turismo internacional e nacional nas comunidades locais;

5. Incrementar mecanismos para a promoção de uma melhor formação técnicoprofissional;

6. Considerar formas complementares ao turismo "sol e praia";

7. Melhorar as condições de acessibilidades;

8. Reclassificar as unidades de alojamento;

9. Promover o artesanato como forma de enriquecimento da oferta e criação de pequenas e médias empresas. 
Preservação do ambiente

1. Controlar o desenvolvimento e a localização adequada dos equipamentos;

2. Evitar o agravamento dos problemas geradores de desequilíbrios ecológicos;

3. Evitar a deterioração da paisagem;

4. Deter a destruição dos sistemas ambientais.

Propunha-se a criação de Regiões, Áreas, Unidades e Centros Turísticos. A divisão resultante não coincidia com divisões administrativas e provinciais, mas ajustava-se a algumas delas. O Plano assinalava a necessidade de elaborar Planos Regionais e de Planos de Urbanização dos Centros Turísticos com um crescimento mais significativo.

Sublinhava-se que, de acordo com a importância do setor turístico para o desenvolvimento económico e social, se deviam aplicar atuações e estratégias objetivas, não só devido à importância do setor, como também pelas fragilidades dos ecossistemas. Daí, a necessidade de se definirem: a) Valores cautelares, que permitissem que o setor turístico fosse uma realidade sustentável para as próximas gerações, devido às fragilidades dos ecossistemas; e b) Normas regulamentares, desde o cálculo da oferta potencial até às normas urbanísticas e arquitetónicas, considerando a tipologia de alojamentos e capacidades, densidades brutas, percentagens de ocupação e de utilização, cérceas máximas, bem como normas de infraestruturas, propostas como objetivas para os novos investimentos turísticos e necessariamente importantes para os povoados próximos, de forma a potenciar o benefício direto destes.

O Plano concluía que o futuro do turismo dependia de um planeamento e de uma gestão coerentes a diferentes escalas, desde o internacional ao local.

\section{Do Plano aos planos}

A visão estratégica e as propostas expressas no "plano português" tiveram repercussão em documentos seguintes, embora se sinta que a elaboração destes corresponda mais a uma necessidade de cumprir calendário político do que a de atualizar diagnósticos e propostas. Ainda assim, houve a necessidade de estabelecer metas ao nível da sustentabilidade e do marketing, que acabaram por se relacionar com as propostas do "plano português".

No período em que vivemos no país, estava a iniciar-se, precisamente, uma Política de Desenvolvimento Turístico, para o período 1996-2000, no sentido de integrar no desenvolvimento turístico integrado do país os conceitos da sustentabilidade (Troncoso, 1999).

O exemplo da inconstância do Estado em relação ao planeamento turístico do país é a sucessão de documentos: um primeiro, preparado pelo Ministério de Turismo, em 1999, que parte do "plano português" para aumentar a competitividade face à concorrência na região caribenha e a nível internacional, estabelecendo um marco orientador para os investimentos públicos e privados na República Dominicana e tendo em vista a diversificação e a qualificação da oferta e o aumento dos níveis de emprego, melhorando a qualidade de vida dos cidadãos do país; e um segundo (2003 e 2013), decorrente da IV Convenção Nacional de Turismo, como veremos adiante.

Uma outra medida importante, também emanada do Estado, foi a criação, em 2006, do Programa de Prevenção e Segurança para as Zonas Turísticas, aspeto que sempre preocupou os responsáveis pelo "plano português" e da maior importância para a competitividade do destino. 
Com o objetivo de potenciar a interrelação de todos os atores da cadeia global de valor, os responsáveis políticos da República Dominicana optaram por desenvolver o turismo a partir de uma visão mais geral e integrada através dos clusters turísticos estratégicos (Consejo Nacional de Competitividad, 2008), com uma unidade de coordenação para fazer face à escassa visão planeadora de alguns destinos locais no controlo do uso do solo e nas práticas inteligentes de desenvolvimento (sustentabilidade ambiental). Trata-se de uma rede de confiança entre os participantes para o apoio a iniciativas para a criação da oferta complementar baseada no património tangível e intangível do destino, incluindo a melhoria das vias de comunicação e sinalização, para facilitar o transporte terrestre de passageiros, assim como desenvolver um plano que garanta condições de salubridade e segurança das comunidades locais (sustentabilidade socio-cultural).

No mesmo ano, o Plano Estratégico de Turismo Cultural (2008), documento pensado para dois anos e da responsabilidade da Secretaria de Cultura, com o apoio do Conselho Nacional de Competitividade, teve em vista posicionar os elementos culturais e naturais como um novo nicho de mercado estruturado, numa concertação entre o setor privado e o Estado. O objetivo principal foi melhorar o nível de qualidade de vida dos residentes dos municípios vinculados aos recursos culturais. Com esta iniciativa, pretendeu-se consolidar o aumento de turistas na República Dominicana, como destino de férias, fortalecendo a sua liderança no segmento cultural e da natureza, como complemento ou alternativa ao segmento consolidado de "sol e praia", através de uma estratégia de diferenciação baseada na imagem de qualidade dos recursos culturais e naturais. Os responsáveis pensavam apoiar a participação birecional dos setores público e privado a nível nacional e local e a integração dos clusters turísticos, com benefício para as comunidades e potenciando as vertentes eco e etnoturísticas ("turismo comunitário”). Neste plano, destacam-se: a) Produtos turísticos já existentes; b) Produtos turísticos potenciais; e c) Elementos de suporte a novos produtos de turismo cultural.

Em particular, as propostas do nosso Plano indicavam a necessidade de as instituições responsáveis adotarem uma visão integral de melhoramentos da Zona Colonial de Santo Domingo, dado o seu papel fundamental no turismo da capital. Assim, em 2009, o Conselho Nacional de Competitividade promoveu um diagnóstico sobre Santo Domingo como destino turístico e, em 2011, o Banco Interamericano de Desenvolvimento (BID) e o Ministério do Turismo (MITUR) promoveram o Programa de Fomento ao Turismo na Cidade de Santo Domingo. O objetivo passou por definir medidas de desenvolvimento da Cidade Colonial de Santo Domingo como destino cultural, contribuindo para a diversificação da oferta turística. $O$ programa foi construído com base na opinião dos atores locais e com base num estudo de mercado que incluiu 1500 inquéritos a turistas nos aeroportos internacionais e na Cidade Colonial. Definiram-se projetos prioritários no âmbito da conservação e valorização do espaço público, expressos no Plano de Revitalização Integral da Cidade Colonial de Santo Domingo, que teria efeitos no espaço urbano e se revela determinante para a melhor imagem da capital dominicana.

O "plano português" previu, assim, um conjunto de medidas inovadoras que acabariam por ser assumidas por outros documentos seguintes. Em termos de macroanálise, a finalidade de estabelecer uma estratégia que permitisse passar do modelo de "turismo de enclave", caracterizado por uma ausência de alargamento do benefício às populações locais em relação aos recursos infraestruturais construídos e de uma escassa integração da comunidade na cadeia global de valor, para um modelo de turismo mais sustentável, foi sistematizado 
posteriormente (Secretaría de Estado de Turismo, 2003), com base em aspetos fundamentais: infraestrutura e ordenamento territorial, formação de recursos humanos, promoção, salubridade, segurança pública e integração da comunidade.

\section{Um desenvolvimento sustentável no futuro?}

O destino turístico é entendido como um espaço geográfico, social e económico com determinadas características e inter-relações, a partir das quais se oferecem experiências turísticas aos seus visitantes, mas também oportunidades e qualidade de vida aos seus habitantes, as quais se refletem em todos os utentes do espaço. $O$ aumento da pressão humana sobre a zona costeira traz, porém, o risco de uma redução substancial do equilíbrio dos ecossistemas, ameaçando inclusivamente áreas protegidas. Os múltiplos usos da zona costeira têm criado, em todo o mundo, especiais atenções e compromissos sociais, como a sustentabilidade, a eficiência económica e a equidade. Para intervir no desenvolvimento turístico equilibrado será necessário atuar sobre o conjunto.

O turismo tem tido um papel fundamental no desenvolvimento económico da República Dominicana, nas últimas duas décadas, após a presença portuguesa dos consultores. Tem contribuído, designadamente, para o crescimento de emprego, para o fortalecimento de outros setores (construção civil, transportes e comércio) e para a melhoria das infraestruturas (estradas, aeroportos e redes de água, eletricidade e esgoto) e, também, para a internalização do país e da sua cultura e valores, em articulação com as agências de promoção turística distribuídas por todo o mundo.

Com a promulgação da Lei n. ${ }^{\circ} 158$, de 2001, reforçou-se o fomento turístico dos polos de escasso desenvolvimento e de novos polos e localidades de grande potencial, criando-se $o$ Fundo Oficial de Promoção Turística. De igual forma, criou-se o Conselho de Fomento Turístico, para aplicar a Lei, presidido pelo Secretário de Estado do Turismo.

Os produtos turísticos que predominam são, principalmente, o turismo de "sol e praia", golfe, desporto e congressos e convenções, embora já se sinta o crescimento do ecoturismo e turismo cultural. A oferta hoteleira é variada, pois as unidades oscilam entre 100 e 1000 quartos, mas mais frequentes são os alojamentos de 300 a 400 quartos. A categoria dos "resorts" é fundamentalmente de 4 e 5 estrelas, construídos em locais sem infraestruturas e escassa oferta complementar, o que reforçou o objetivo de separar ainda mais a população residente de qualquer benefício. Mas mais recentemente, à parte a tipologia do "hotel-resort", cresce o número de hotéis com menos capacidade (entre 10 e 80 quartos), localizados em cidades vocacionadas para o turismo cultural e também na costa, com uma variada oferta de serviços complementares. ${ }^{4} \mathrm{Em} 2011,56 \%$ dos hotéis tinham mais de 300 quartos e apenas $22 \%$ tinha menos de 100 quartos. Ainda assim, 62\% dos quartos estavam concentrados em dois destinos: Bávaro-Punta Cana e Puerto Plata (Corona, 2011). Os principais mercados emissores de turismo para a República Dominicana têm sido os Estados Unidos e o Canadá, seguidos dos países da Europa, do grupo da América Central, do Sul e Caraíbas e do grupo do resto do mundo.

Se, por um lado, o crescimento turístico tem sido explosivo, tal nem sempre contou com os padrões de sustentabilidade, designadamente ambiental. Algumas construções foram erigidas sem respeito integral pelas regras: hotéis sobre solos húmidos e mangais e sem estudos de impacto ambiental (vigentes desde 2000), destruição de barreiras naturais de coral, funcionamento inadequado de despejos de águas residuais e lixos, salinização da água

\footnotetext{
${ }^{4}$ Os números referem-se ao cruzamento de informações provenientes de dados recolhidos com diferentes origens e que confirmam as principais fontes (Banco Central da República Dominicana e Secretaria de Estado do Turismo).
} 
potável e privatização das praias. Estes custos ambientais nem sequer têm sido compensados por impostos, pesados pagamentos ou retorno de lucro, por parte dos investidores prevaricadores. Aliás, o crescimento deste tipo de investimento, cuja recuperação do mesmo se faz a curto prazo, implica que, do ponto de vista do investidor, os impactos ambientais a médio e longo prazo não sejam importantes.

Em termos de sustentabilidade socio-cultural e económica, a adoção inicial do "tudo incluído" veio ao encontro das necessidades de isolar o turista de uma envolvente deficitária em infraestruturas viárias e transportes, prejudicando o acesso aos aglomerados próximos e à cultura local. Essa falta veio sendo atenuada, mas ainda se sente um défice de trocas e relacionamento social entre turista e residente, o que não estimula o aparecimento de restaurantes e lojas em maior número e qualidade fora dos complexos turísticos, para além de que a venda das artes locais dentro desses complexos traz o maior lucro para os proprietários e gestores destes, resultando num afastamento ou numa dificuldade no negócio turístico por parte dos produtores locais e das suas micro ou pequenas empresas. A atividade turística pode ser uma oportunidade a curto e a longo prazo, ou seja, um fator de dinamismo económico. Mas apenas será sustentável se for capaz de incorporar a comunidade local como agente produtor de cultura e conhecimento. Além do mais, assim se cria um sentido de pertença e uma responsabilidade coletiva perante o destino turístico no seu todo face a externalidades negativas.

Este quadro de imagem turística estereotipada, baseada em investimentos encravados, de baixo preço, de escassa regulação estatal, de escasso ordenamento territorial e de diminuto investimento em infraestruturas e controlo ambiental e de exclusão social, apesar de casos excecionais (Punta Cana e La Romana) que só confirmam a regra, foi percecionado no Plano de 1996 e atenuado, é certo, nos anos mais recentes.

Torna-se evidente, com confirmação nas estatísticas do Banco Central da República Dominicana, que o setor turístico da República Dominicana tem sido uma das atividades mais dinamizadoras e influentes de desenvolvimento, a par dos setores das telecomunicações, construção, energia, água e comércio, e tem margem de crescimento. Em paralelo com os produtos relacionados diretamente com o "sol e praia", a intenção do turismo dominicano alarga-se ao golfe e ao turismo residencial, procurando nichos de procura mais exigentes e elevados em termos de poder de compra, o que se distingue das lógicas investidoras de há duas décadas. Igualmente se prevê continuar com os investimentos em infraestruturas portuárias e o aumento de ligações aéreas com outros destinos.

A complementar esta dinâmica, fala-se de criar uma "marca-país" para a República Dominicana, à qual seja possível associar: o "sol e praia" de Punta Cana, a história e cultura de Santo Domingo, a natureza de montanha de Jarabacoa e Constanza. E também atualizar os dados do desenvolvimento recente e projetar o futuro em função da marca e dos anseios dos agentes políticos e económicos, mas sobretudo que se impeça que o desenvolvimento continue a ser pautado pela improvisação, numa articulação perfeita entre o setor público e o setor privado, com participação do Estado dominicano. Neste sentido, o Ministro da Economia, Planeamento e Desenvolvimento e o Conselho Nacional para a Reforma do Estado, dando cumprimento à Lei de Planeamento e Investimento Público (Lei n. ${ }^{\circ} 498$, de 2006) e ao compromisso assumido no Encontro pela Unidade Nacional para Enfrentar a Crise Económica Mundial, apresentaram publicamente a Proposta de Estratégia Nacional de Desenvolvimento 2010-2030. Aquela Lei apresenta a estratégia de desenvolvimento como um instrumento de planeamento para definir a imagem objetiva do país, no longo prazo, e os principais compromissos do Estado e dos atores políticos, económicos e sociais, tendo em conta a sua 
viabilidade social, económica e política. Para tal, seria necessário identificar os problemas prioritários a resolver, as linhas centrais de ação necessárias para a sua resolução e respetivo incremento.

Note-se que ainda estão por inventariar as necessidades em infraestruturas das zonas turísticas de um modo consensualizado entre privados e organismos públicos, bem como um plano realista de investimento nas zonas de alto potencial de desenvolvimento imediato (Barahona, Miches, Constanza e Baía de Ochoa). Em relação às infraestruturas, o investimento ainda se apresenta escasso, designadamente, em serviços básicos como redes de águas e esgoto e estações de tratamento de águas residuais; apenas na zona Norte, se sente um maior investimento público do Estado.

Segundo o empresário Rainieri (2014), os novos investimentos turísticos do país devem basear-se nos seguintes pontos, tendo como base Punta Cana: construídos em baixa densidade populacional e de forma sustentável, numa lógica familiar e de convivialidade e potenciando as oportunidades do turismo náutico. ${ }^{5}$

Já em 2015, o Ministro do Turismo assegurou que o Programa de Fideicomiso Turístico, iniciado pelo Banco de Reservas da República Dominicana e pela Fiduciaria Reservas, contribuirá para um maior crescimento do setor turístico, tendo em vista a meta de 10 milhões de turistas, em 2022. O programa passa por criar conceitos e metodologias alternativas para o incremento dos novos projetos turísticos, designadamente através de vias de conciliação entre os agentes envolvidos, bem como facilitar o acesso ao crédito. ${ }^{6}$

\section{Nota conclusiva}

Em duas décadas, de 1995-1997 até à atualidade, o mundo transformou-se e a República Dominicana também. Não havia Internet e os telemóveis escasseavam. Chegavam ao país cerca de um milhão de turistas; hoje, são mais de 4 milhões.

O Plano executado por consultores portugueses deixou sementes que germinaram, designadamente nas recomendações sublinhadas nos aspetos da sustentabilidade e da cultura, temas cada vez mais presentes no universo do planeamento turístico à escala mundial. Contudo, crê-se que Portugal perdeu uma oportunidade, pois tendo sido o financiador e mentor (através dos seus consultores técnicos) junto do Banco Interamericano de Desenvolvimento, não aproveitou esta ação para integrar, de imediato, estratégias de estreitamento diplomático e económico.

A República Dominicana tem tido, ultimamente, novos impulsos no desenvolvimento e uma abertura crescente ao exterior. Em relação a novos investimentos turísticos, mais do que em hotéis que não criam por si só um destino, a tendência poderá estar no alojamento integrado com oferta complementar, nas infraestruturas, na gestão do ambiente, na segurança, na promoção e interligação com as comunidades locais próximas, tal como há vinte anos preconizámos.

Será que Portugal e os portugueses farão parte deste futuro?

\footnotetext{
${ }^{5}$ A importância deste empresário no processo evolutivo do turismo na República Dominicana confere relevância às suas palavras intituladas "Oportunidades para el desarrollo turístico e inversión del Grupo Puntacana" (Rainieri, 2014).

${ }^{6}$ Os dados referem-se ao cruzamento de informações provenientes de notícias recolhidas na Internet, datadas de novembro de 2015.
} 


\section{Referências bibliográficas}

Arespacochaga, A. (1968). República Dominicana - Desarrollo turístico. Informe sobre el desarrollo turístico de la República Dominicana. UNESCO.

Sociedade Nacional de Empreendimentos e Desenvolvimento Económico (1997). Plan nacional de ordenamiento del território turístico de la República Dominicana. Informe Final (7 vols). Lisboa: SNEDE.

Consejo Nacional de Competitividad (2008). Plan nacional de competitividade sistémica de la República Dominicana. Santo Domingo: Consejo Nacional de Competitividad.

Corona, M. B. (2011). Análisis de República Dominicana como destino turístico. Monografia não publicada. Mangorrinha, J. (2015, 11 dezembro). Portugal e República Dominicana. Publituris.

Ministerio de Economía, Planificación y Desarrollo (2009). documento base de la propuesta de estrategia nacional de desarrollo 2010-2030. Un viaje de transformación hacia un país mejor. Consejo Nacional de Reforma del Estado.

Ministério de Turismo (1999). Plan estratégico de desarrollo turístico de la República Dominicana. Santo Domingo: Ministério de Turismo.

Rainieri, F. (2014, 6 novembro). "Oportunidades para el desarrollo turístico e inversión del Grupo Puntacana" (Discurso a 5 de novembro).

Secretaría de Estado de Turismo (2003). Plan nacional del desarrollo turístico 2003-2013. Diagnosis Nacional, tomos I, II, III e catálogo de proyectos. Santo Domingo: Secretaría de Estado de Turismo

Troncoso, B. (1999). Propuesta para una política de desarrollo turístico sostenible. Documento online.

JORGE MANGORRINHA é Professor Universitário e Coordenador Técnico do Plano Nacional de Ordenamento do Território Turístico da República Dominicana. Endereço institucional: Universidade Lusófona de Humanidades e Tecnologias, Departamento de Turismo, Campo Grande, 376, 1749-024 Lisboa, Portugal.

Submetido em 15 setembro 2016

Aceite em 28 março 2017 